\title{
The Approaches of Design Knowledge Integration in Innovation Design*
}

\author{
Fei Hu \\ School of Art and Design \\ Guangdong University of Technology \\ Guangzhou, China \\ philhu2002@hotmail.com
}

\author{
Xipeng Shen \\ School of Art and Design \\ Guangdong University of Technology \\ Guangzhou, China \\ 623659246@163.com
}

\author{
Xi Zhang \\ School of Art and Design \\ Guangdong University of Technology \\ Guangzhou, China \\ zhang-xi916@163.com
}

\begin{abstract}
This paper reveals the identity which integrated innovation and design innovation have in solving complex problems and preferred matching integrated innovation elements, and the differences in the field of knowledge and integration standard. In the face of a wide range of interdisciplinary knowledge, we will take semiotics as example in this paper, and analyze the possible integrated approach of design knowledge like adduct, union, function and direct product. Then indicate that, the design knowledge is a structure of " $T$ " style with the design as the backbone. The integrated approach of design knowledge is the compound direct product of interdisciplinary. Therefore, the design personnel training should focus on the interdisciplinary " $T$ " style knowledge structure and integrated innovation ability.
\end{abstract}

Keywords-Integrated innovative design; "T" style design knowledge; compound direct product

\section{INTRODUCTION}

The development of design theory brings new challenges to design education; more scholars will be devoted to design education study such as design knowledge, design ability and design training mode. The increasing improvement of life quality and culture made design activities more complicated, which means that designers had limited on technology innovation. Design innovation is an innovation process of integrating existing resources and then creating the optimal solution. The appropriate training model which has this ability to innovate has high research value, and training is the basis of the design knowledge with depth understanding. Therefore, this paper which based on the process of design activities change will discuss knowledge integration approach and logic.

*Subject source:supported by higher education teaching reform project of Guangdong Province Education Department on "T style integrated innovation design knowledge system and enterprise cooperative education mechanism research"(No.JGXM002); supported by Guangdong Innovation Research Team Program on "Industrial Design Integrated Innovation Research Team" (No.2011G089); supported by high level talent project of colleges and universities in Guangdong Province " Semiotic Approach to Product Architecture Design ".

\section{THE IDENTITY OF INTEGRATED INNOVATION AND DESIGN INNOVATION}

Integration is a creative fusion process. Marco Iasiti (1998) first proposed the concept of technological integration: "Enterprises improve the research-and-development skills through comprehensive application on good resources for innovation, tools, and methods for technical problems"[1]. Nancy Staudenmayer and H.K.Tang (1998) proposed the Innovation collection of technology, knowledge and information from the perspective of organizing internal resources, which highly correlated to the concept of "system integration"[2], Best (2001) discussed.

On this basis, scholars put forward the concept of integrated innovation, which emphasizes on the injection of creative thinking in the process of combining elements. It is not integration that elements are permutated and combined in the normal way ; only when forming an organism composed by appropriate elements, mutual complementary advantages and most reasonable structure after the active selection, optimization and collocation, the adaptation of elements, the organism is truly integrated. Integrated innovation has four characteristics [3]: (1) complexity of objects : complex system interwoven by various positive and negative feedback structure and nonlinear coupling; (2) elements of integration: different levels of ideas, knowledge, technology both inside and outside of the organization achieve optimal matching and optimal combination, according to the optimal combination; (3)dynamic process: with the increasing constantly updated resources and knowledge, we need constantly reorganization and matching; (4) amplification of effectiveness: through the reasonable allocation of the proportional relationship and interaction ability between resources, the structure of the whole innovation resources tends to amplify the overall function dramatically. Thus, the key of integrated innovation is not the supply of technology, but the relationship between the increasingly rich technical resources and the effective applications. 
Scientific research reveals and discovers what is the rule of the world "to be", as well as pays attention to what things are. Technical means tell people what things "might be". While Design, combining all these knowledge to change the world, just concerned about what things "should be "[4]. If design is regarded as "a purposeful human creative activities, the design objects can be defined as an association system between "things" factor (time, place, person, etc.) and "objects" factor (technology, material, craft). Beginning with the clear objectives and the objective system design research, design activities make innovative design by means of choosing method, importing knowledge and restructuring resource, in continuous evaluation and feedback, adjusted to the most appropriate collocation and combination, to solve the problem and maximize the value.

When contrast technology integration and design innovations, we can find something as follows :In terms of the logical starting point of view, technology integration and design innovations are both began with grasping the needs :The technology integration, which originates from the different demand of technologies for the product diversification, reverse needs from the perspective of "things" ;while, Design innovation, based on the exploration of the life style and behavior of people, discovers needs from the perspective of "human", "enterprise" and "society". From the point of view of the innovation process, they both focus on matching innovative elements and relationships: Technology integration based on original innovation knowledge and technology for the material and elements to find the best match or the optimal combination between products meeting the needs and the rich technical resources to be supplied. Design innovation is not just to pursuit a breakthrough of a single element, but to seek for solutions through exploring the possible relationship between technology, materials, structures, processes, etc.. From the evaluation standards, they both depend on external constraints of the system. Technological integration and design innovation are some different in the source points and results, but in terms of the relationship between the objective and means, they have high identity (Figure 1).

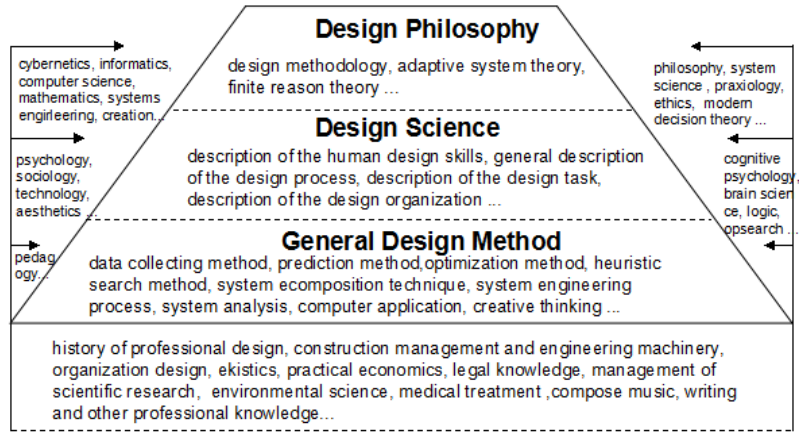

Fig.1. Identity relationship between design innovation and integrated innovation

\section{INTERDISCIPLINARITY AND INTEGRATION OF DESIGN KNOWLEDGE}

The development of politics, economy, and society brings human diversified life, thus, design activities become more and more complicated. Designers need to delve into what people are (who), in what context (when \& where), what requirements (what),and the reasons behind the demand

(why), understanding the purpose of the design accordingly, then organize technology, material, technology and so on, through the design means to express (how). This process determines the designer's diversified and comprehensive design ability. Corresponding to this, the ability to found design problems needs to integrate sociology, economics, marketing, anthropology, psychology knowledge and so on; the ability of problem analysis needs to integrate management, logic, environmental engineering, ethics knowledge and so on; the ability of problem solving needs the integration of thinking science, cryptology, materiality, electronic technology, information technology, machinery manufacturing, processing technology knowledge and so on; the ability of results presentation needs knowledge integration of art, aesthetic, linguistics and communication, and soon. In this sense, design knowledge go across the material of natural science and mental domain of social science fields[5].

$\mathrm{Li}$ Yang and $\mathrm{Li} \mathrm{Xu}$ vaguely divided design research and design science into professional design knowledge, genera design method, design science and design philosophy four layers[6](Figure2), and consider that professional design knowledge has a directly strong influence on the study of the above three levels, vice versa. We explain the fuzzy design boundaries and content's cross on the basis of it. Natura science and social studies knowledge of the oceans bit integrate design knowledge to become rivers, and designer solutionsfocused thinking, from the clear design goals, problem analysis and design to creative problem solving, artistic expression and exchange of experience designing activities.

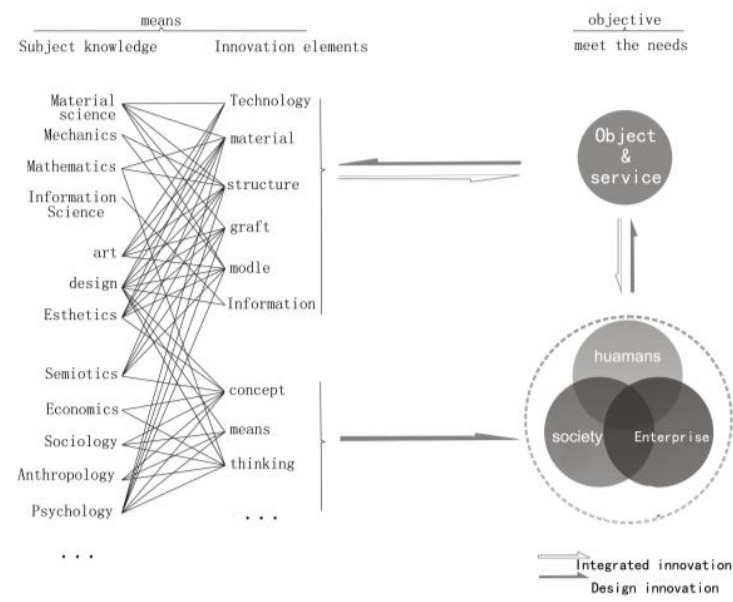

Fig.2. Design research and design science (Li Yang and Li Xu,1987)

Perkins (1986) thinks that design knowledge is related to the purpose, structure, model and demonstration four design elements[7]: ( 1 ) design requires a purpose, in order to guide the final design results; (2) the structure can interpret different artifacts, such as objects, products and construction; (3) the model can describe how things operate in detail; (4) demonstration can explain the current work why adopt those principles. This shows that the design knowledge is descriptive rather than conceptualized, it is an associate and not independent, it is also abstract rather than concrete, it is 
subconscious rather than preventative [8]. Its description is that design knowledge cannot be set a single constantly to define, it is precisely because there is no clear definition of design knowledge that makes the development of the design concept itself not inherently limited; its relevance refers to the design knowledge is the mix of natural science knowledge and social interdisciplinary knowledge to form, not independent knowledge structure. The abstract is that design activities is fraught with uncertainty and ambiguity from question to solution, specific theoretical knowledge is difficult to solve; subconscious refers to the design knowledge is no other superficial subject knowledge accumulation, but through some kinds of guide focus to knowledge solutions. From the characteristic of design knowledge it is not difficult to find that it's more vague to definite design boundary, but not unrecognizable.

Excellent designers always have a tacit agreement to the clever use of his knowledge of the subject, to convert it to become an effective means to better meet the design goals. Science activities are characterized by "problem focused", and the feature of design activity is "solution focused"[9]. Designers of thinking by way of searching his academic knowledge integrated into specific design activities, skillfully developing solutions and development problems to match. Therefore, the design knowledge with the purpose of integration is constructive and creative mindset, which is different from inductive and deductive reasoning. March believes that it is a kind of adductive by way of thinking; tracing is to explain what is known is inference to the best explanation is speculative logic. Designer is based on this logic, following the "adaptive" system, trying to regulate internal factors, internal and external balance approaching equilibrium, the solution is focused on the balance. Scientists working on discovery rules and designers also want to achieve the best results. Therefore, the design knowledge to design problems has targeted solutions focused to thinking clues integrated orientation.

\section{INTERDISCIPLINARY INTEGRATION PATH OF DESIGN KNOWLEDGE}

Generally in the interdisciplinary study, subject name is cross juxtaposed to form "A + B" model; in recent years, emerging design semiotics, design psychology, design ethics has been true. Taking semiotics as an example, analyzing integrated path of design knowledge interdisciplinary.

\section{A. From "design+" to "design U"}

Firstly, Can the elements of design and other subjects add together just directly? The basic principle of the arithmetic is adding the similar item to get the sum, as we cannot add three apples and two watermelon directly; but if unify to the concept of "fruit", 3 fruit (apple) +2 fruit (watermelon) $=5$ fruit. Similarly, design and semiotics itself are not homogeneous features; but rising to the vision of the humanities, some parts of design and some parts of semiotics can completely add up. But, which parts on earth they are? Because of the generality and uncertainty in design and semiotics, this matter left to us to think about. At least, as "man-made things science", design has something in common on "man-made" with semiotics which can express conventional or group consistent expression of ideas, concepts and meanings by specific image.

Secondly, is there simple relation of adduct between design and semiotics? The purpose of adding is to obtain the sum. However, is the aim of intersecting between design and science to seek sum? Absolutely not.

Thirdly, design + symbol $=$ design $\cup$ symbols. To the results, even brought in the field of the humanities, it will only occur with the union of semiotics and design science-contains containing all the elements of design and semiotics but not any collection of other elements; and then generalize infinitely to make "design $\cup$ symbol" containing everything. And if the "design U symbol" is all-inclusive, does value exist in design semiotics?

\section{B. From "f: symbol $\rightarrow$ design"to "design $\times$ symbol"}

Obviously, the wrong relevance "design + symbol" led to the wrong conclusions "design $\cup$ symbol". However, what is the relationship between design science and semiotics?

Firstly, we need to clear the cross position. Whether we stand inside the circle of design or the circle of semiotics? Although the boundary of design and semiotics are fuzzy, after all, two different circles they are. Therefore, it must be clear: we are introducing semiotics standing on the field of design science.

Secondly, we need to clear the direction where we importing to. Since standing in the inner circle of design science, semiotics means something "import" instead of "output" for design; we can use the function arrow "f: $\mathrm{x} \rightarrow \mathrm{y}$ " to represent the relationship between the two:"f : Symbol $\rightarrow$ design." "F" indicates a correlation, "f: $x \rightarrow y$ " means set $x$ map to set $y$; "f:symbol $\rightarrow$ design" means bring the concept, theory, and method which come from semiotics in design, then to solve problems on design discipline more effectively, and to promote the study of design disciplines. Therefore, in "f: symbol $\rightarrow$ design", "design" is the objective, "symbol" is the means; No matter Saussure's semiotics or Peirce's logic semiotics are all concepts and methods used for design research; and this consistent with the discipline positioning of semiotics: interdisciplinary methodology, "general semantics" and "cultural logic". So, is design semiotics the "semiotics of design"? design semiotics is a semiotic study on design phenomenon or outcome, isn't it? Or, is design semiotics "the design science of symbol? Is design semiotics a kind of activity for creating symbol?

Thirdly, it is necessary to define the result of mapping. Now that we want to bring other disciplines into design science, the knowledge or method of other disciplines must be able to reveal the problems that the design science itself failed to reveal or ignored; or to help design science more effectively solve the existing problems. Otherwise, such a "cross" and the "span" will lose its value; and this interdisciplinary will also become a pseudoscience. Crossover study on design science and semiotics may construct the "Design $\times$ symbol" collection. It should be stressed that, what the " $x$ " is not the product of arithmetic, but the direct product of set theory. Direct product " $x \times y$ " means all ordered pair of the collection which the first element belongs to $\mathrm{x}$ and the second element belongs to $\mathrm{y}$. The direct product "Design $\times$ symbol" meant to construct an 
orderly relationship between design elements and semiotic elements. so, such "cross" disciplinary research can make sense; and then find the "frame shift" or "displacement" of design science through study on semiotics, to achieve mutation on design science, and such "cross" disciplinary research can reflect the value of "crossover". In addition, it may be able to reveal the possible direct product isomorphic relationship between design science and semiotics.

\section{AS DESIGN KNOWLEDGE OF INTERDISCIPLINARY COMPOUND DIRECT PRODUCT}

Firstly, the integration of design knowledge is not the union set of interdisciplinary knowledge, namely $\mathrm{DK} \neq\{\mathrm{d}\} \cup\{\mathrm{x} 1\}$ $\cup\{x 2\} \cup \ldots \cup\{x n\}$. Although design knowledge may be a huge knowledge network, but is not infinitely include all the knowledge of various disciplines.

Secondly, if we use the $x n$ variable represent other subject knowledge, the function "f: $\mathrm{xn} \rightarrow \mathrm{d}$ " stressed the relevance between design science knowledge and other disciplinary knowledge, but because the other disciplinary knowledge is not available for formula computing, the function can hardly indicate the complex relationships between them.

Therefore, $\mathrm{DK}=\{$ Design $\} \times\{\mathrm{xn}\}$. Direct product relationship shows the orderly correlation construction, in which solution-focused thinking play a bridging role in, between design knowledge elements and other disciplinary knowledge elements[10]. Design knowledge integration is not to integrate the all elements of other disciplinary knowledge, but integrate selectively and creatively based on objectives and conditions, so that by solutions-focusing, the knowledge element can be translated into a more effective means for solving design problems.

However, how design knowledge conduct with interdisciplinary integration by direct product? What is the integration path, $\{$ design $\} \times\{x 1\} \times\{x 2\} \times \ldots \times\{x n\}$, or $\{$ design $\} \cup(\{$ design $\} \times\{x 1\}) \cup(\{$ design $\} \times\{x 2\}) \cup \ldots$ $(\{$ design $\} \times\{x n\})$ ? The former emphasizes the orderly correlation between design and other disciplines, and the crosscorrelation within the inter-disciplinary; the latter will expand design knowledge by integrating other disciplinary orderly correlation part, with service design as a carrier. The interdisciplinary crossover on other disciplines does not clearly express the orientation of design, and through some kind of orientation, the result of crossing cannot be translated more effectively to solve the design problems, and meanwhile lose the dominance of design. The integrated approach of design knowledge is closer to the latter, with its own as the carrier, and by means of solutions-focused orientation, design takes in some parts of other disciplinary knowledge, and then combines into an effective means to solve design problems, therefore, design knowledge's integration may lead to the "T-type" knowledge structures of which design as the backbone.(Figure 3)

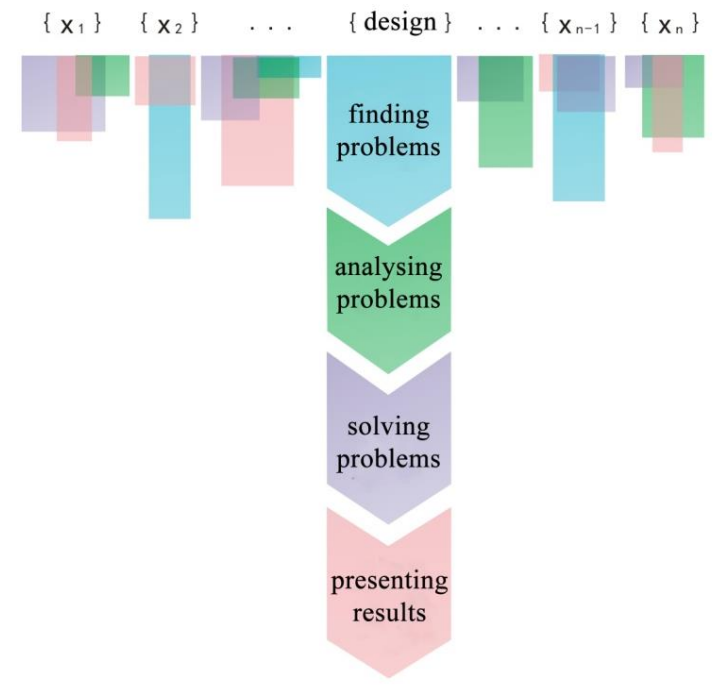

Fig .3. Knowledge composition of "T-type" integrated innovative design

\section{CONCLUSION}

The diversity of society, economy and culture makes the design activities more complicated, which means that the design methods of the past will be difficult to meet the changing needs of people. In the design activities, designers who are faced with the problem is not a single dimension or static, and may involve financial, medical, Internet, manufacturing industries, agriculture, service industry and other industries; designers have to face the enormous challenges caused by different problems. If the multidiscipline knowledge integration is the "thaw", the purpose of design knowledge integration is the "will" -- using breakthrough and disruptive innovation creative solutions to solve the problem; The integration process is under the guidance of creative focus on thinking, the integration of various disciplines in the preferred design innovation elements so that all elements of mutual adaptation innovation, combination, coordinating, and then form a complementary strengths and weaknesses, reasonable structure of the organism, and more widely to find insight of the problem and demand, further to define the problem, analyzing the problem, more reasonable solution to the problem, more perfect presentation design results.

The training goal of the design talents is to make them get the ability to solve the design problems in different industries. Correspondingly, the design knowledge should also show different types of " $T$ " knowledge structure. The design of "T" type knowledge structure exists in the design process, and the ability to accept and absorb; the completion of each design activity, design knowledge will be collated and update, absorption of new knowledge constantly enriched, the revision, the reorganization of " $\mathrm{T}$ " type substructure. And through the next design activities, it reflects the integrated innovation capacity after improvement. Therefore, the goal of design education is to cultivate the integrated innovative design talents with the knowledge structure of " $T$ " type and the integrated innovation capability of the "T" type. 


\section{ACKNOWLEDGMENT}

Masters in USD Joint Laboratory, School of Art and Design, Guangdong University of Technology, had contributions on design innovation discussion. And Prof. Keiichi Sato in Institute of Design, Illinois Institute of Technology, gave many advices on the theory modeling.

\section{REFERENCES}

[1] M. Marco Iansiti, Technology Integration:making critical choices in a dynamic world, Boston:Harvard Business School Press, 1998.

[2] J. H.K.Tang, An integrative model of innovation in organizations. Technovation, 1998,pp.297-309.

[3] J. Xiangyi Lin, Knowledge Integration Modes in Integrative Innovation. Scientific management research, 2011,pp.16-21.
[4] M. Herbert A. Simon, The sciences of the artificial, Liberation Army Publishing Press, 1988, p.130.

[5] M. Fei Hu, Chinese traditional design thinking mode exploration, China Building Industry Press, 2007,pp.5-7.

[6] M. Shuo Yang and Li Xu, Human reason and design science -the exploration of human design skills, Liaoning People's Press, 1987, p.30

[7] M. Perkins,D, Knowledge as design, Hillsdale NJ:Lawrence Erlbaum Associates, 1986, p.95.

[8] M. Fei Hu, Asked design, China Building Industry Press, 2011, pp.24-26.

[9] M. Nigel Cross, Designerly Ways of Knowing, Huazhong University of Science and Technology press, 2013,p.19.

[10] M. Fei Hu, Design Semiotics and product semantics, China Building Industry Press, 2012, pp.21-22. 